\title{
Scheduling Oriented Improvement of Kanban Card Resupplying In Logistic Systems at Automotive Industry
}

\author{
Taher Taherian \\ Department of Industrial Management \\ Faculty of Engineering \\ Naser Khosrow Institute of Higher Education,
}

Saveh, Iran

\author{
Samira Bairamzadeh \\ Department of Industrial Engineering \\ Faculty of Engineering \\ Tarbiat Moallem University, \\ Karaj, Iran
}

\begin{abstract}
Kanban is a pull production system that is very useful in Automotive Production Industry. Logistic systems in automotive industry, tries to apply the best system of logistic to supply the production lines and stations by bringing the parts and all requirements in best quantity and timing in order to come off the JIT specifications. In this article we try to exert a sequencing concept in Kanban card rotations to minimize the line shortage of parts causes stop in production procedure. Minimizing the Resupplying Cycle Times in production lines lead to less quantity of shortages that's one important purpose of lean production. We introduce an appropriate sequencing and scheduling objective function related to Kanban card rotations to minimize some criteria affects the line inventories and causes some improvements on probable shortages. To know the weights of each job we used the Shannon's Entropy method combined with SAW decision making method and we solved the sequencing and scheduling problem with total weighted tardiness objective function, using VNS heuristic method. To show the improvement and positive effects of our method we presented a real world case study and applied our model to a real world case study to observe the improvements in backlogs and tardiness in Kanban resupplying. Finally we presented the achieved improvements.
\end{abstract}

\section{General Terms}

Sequencing and scheduling, Shannon's Entropy, Pull production systems.

\section{Keywords}

Kanban, Just-in-Time, Production Systems, Scheduling, WSPT

\section{INTRODUCTION}

Kanban is originated from the Toyota Production Systems (TPS) which its purpose is to control the inventory levels, raw materials and supply the component parts. Kanban cards are key parts of a Kanban system that uses cards as a signal that determines need to move materials inside a production facility or move materials from a supplier to the production facilities. Gravels et al. (1995) [1] , defines the kanban as Material Flow Control Mechanism that controls the appropriate quantity and time of production of necessary products. Framinan et al. (2006) [2] presented a card controlling procedure for constant work in process systems.Pettersen and Segerstedt (2009) [3] evaluated the differences between Kanban and CONWIP with a simulation study over a small supply chain with restricted amount of work-in-process (WIP).Junior and Filho (2010) [4] searched variations of the kanban system and presented a review and classified the all kind of kanban in literature. Sipper and Bulfin (1997) [5] presented the kanban system with two communication signals or dual card kanban system.
Rabbani et al.(2009) [6] evaluated the multi-stage supply chain system, controlled by kanban system .Tardif and Maaseidvaag (2001) [7], Assumed kanban with unstable demand and considered an adaptive kanban as an alternative to material flow control. Chaudhury and Whinston (1990) [8] proposed an auto adaptive kanban production system which is a similar to kanban system in its structure.Yang and Zhang (2009) [9] studied the performance and parameter design optimization of a Kanban system in a multi-stage and mixedmodel assembly line without stockouts. Mohanty et al. (2003) [10] presented a reconfigurable kanban system with lower inventory costs. Andijani (1998) [11] presented a multicriterion approach for kanban allocations in a single-item, multi-stage, serial production system. Shahabudeen and Sivakumar (2008) [12] presented an algorithm for the design of single-stage adaptive kanban system because he considered that the traditional kanban system with fixed quantity of cards work disappointing in unstable environments.Turner et al.(2012) [13] proposed a general case for solving the problem of Effective application of systems engineering in rapid response environments by combining a services approach with a kanban-based scheduling system to systems engineering. Al-Tahat and Mukattash (2006) [14] tried to create a scheme for production control in Kanban-based JIT environment and developed a synchronized mechanism for a single stage and single product kanban in production line. Hou and $\mathrm{Hu}$ (2011) [15] developed an integrated MOGA approach that determined the Pareto-optimal kanban size for Just-intime systems considering that the kanban size and determine the inventory level of WIP or purchasing parts and they wanted to define the feasible kanban size and number.

What we want to prove in this article is how changing the sequences of each kanban card may lead to less quantity in probable shortages originated of variety problems and erratic delays in feeding and supplying procedure. We must choose an appropriate scheduling objective function to minimize a parameter is very impressive on kanban resupplying cycle time. In this text we will show that this problem is a single machine scheduling process minimize the total weighted tardiness for each parts and kanban card.

Wang et al. (2010) [16] considered the single machine scheduling and sequencing problems with sum of processing times that are based learning effect. They used the weighted processing time rule and earliest due date rule as heuristics.

Li et al. (2011) [17] investigated how to sequence jobs with fuzzy processing times and predict their due dates on a single machine such that the total weighted possibilistic mean value of the weighted earliness-tardiness costs is minimized. Cheng and Lio (2010) [18] proposed a coordinated scheduling of customer orders (CSCO) system, with the purpose of improving customer order flow time for the order-based 


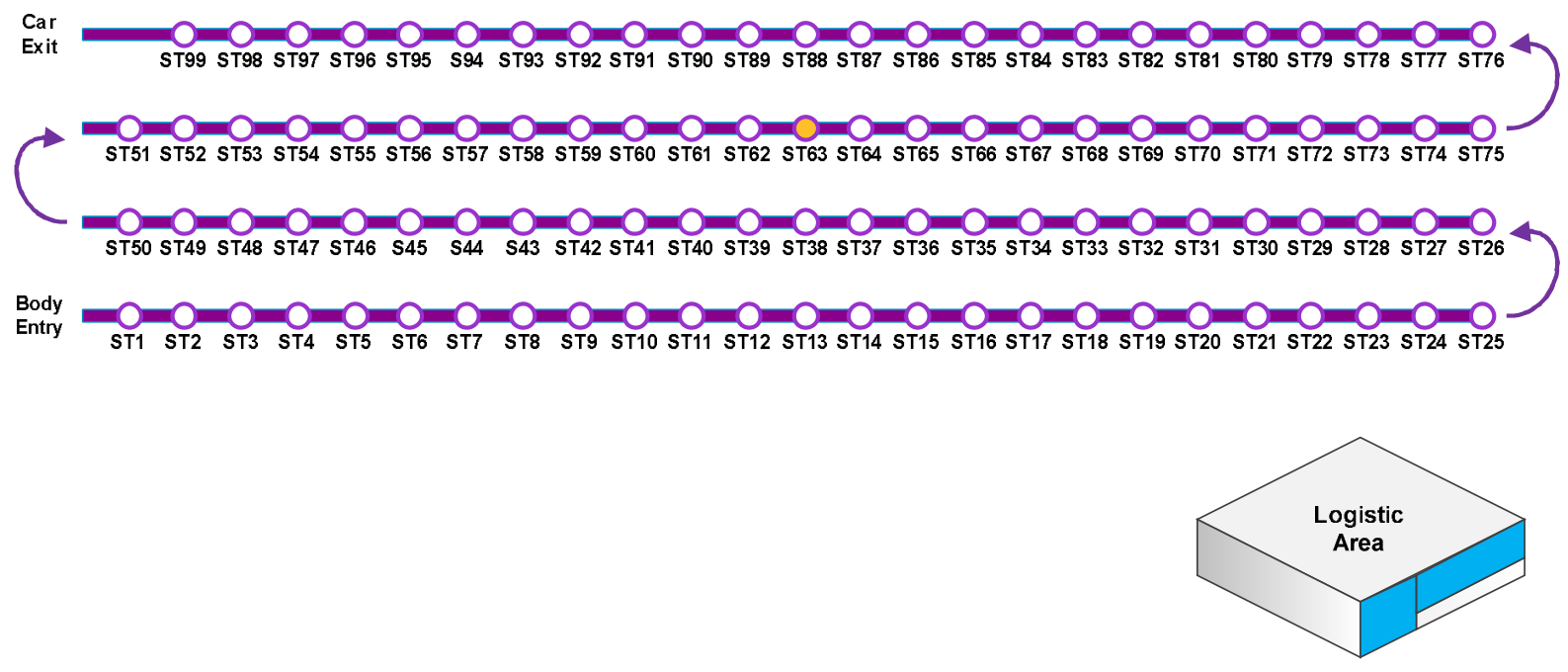

Fig 1: Station sequencing and layout in production area

production system. Erel and Ghosh (2007) [19] generated the algorithms and complexity of customer order scheduling on single machine with family setup times. Sheng and Liu (2009) [20] worked on improving the delivery efficiency of the customer order scheduling problem in a job shop. Wang and Cheng (2007) [21] considered the problem of scheduling customer orders on multiple facilities to minimize the weighted order completion time. Chou (2009) [22] presented an experienced learning genetic algorithm to solve the single machine total weighted tardiness scheduling problem. Wang (2009) [23] developed a population based variable neighborhood search (PVNS) for the single machine total weighted tardiness problem and compared that with the basic VNS. We use VNS algorithm because it is a simple general heuristic algorithm help us to show the objective function alterations.

We want to prove the improvements and we don't need solve the problem in global optimum so even if the model has solved in local optimum, it can be a useful solution helps us to understand the improvement in objective function. Taherian et al. (2011) [24] presented a scheduling based backlog reduction by minimizing the total tardiness in constant work in process systems.

In this article we will introduce the kanban resupplying cycle time and explain our model to improve the kanban resupplying cycle time and backlogs originated of resupplying tardiness using sequencing and scheduling objective function in Section 2. In section 3 we presented a weighting method to calculate the weight or importance of each Kanban Card and finally in section 4 we applied our model to a real world case study and solved the problem using VNS algorithm has been programmed via Delphi Programming Language and the results have been mentioned.

\section{MODEL DESCRIPTION}

In this article we assume an automotive factory assembly line via definite stations of work. The main body enters to first station and some parts available in the store of station 1 will be assembled to the main body and then the body moves the present station to the next and the assembly process continues through the stations one by one, respectively. The automotive assembly line follows the flow shop production and start from first station and move through next stations respectively without any backflow. The kanban is a pull system that has a broad usage in all manufacturing sections. For example kanban can work as a pull system in relationship between customers, manufacturer and supplier in a supply chain. Also we can use it in a production line that brings about a pull system between downward and upward stations. In other form and in logistic systems we can consider a pull relationship between the production line stations and logistic areas to feed required parts under JIT considerations. In this paper we study the kanban in logistic usage to feed the parts in best quantities and timing and develop a method to minimize unpredictable shortages in production lines. There are some allocated jobs to assemble on main body of cars within some seriate stations. The body movement starts at first station and it continues to be completed gradually during stations and exits from last station as a complete car. The example for stations layouts has shown in Fig1.

In each station, some parts are assembled to the output of former station so what is very important in logistic activity is to supply the parts to their prepared palaces and locations in racks in appropriate quantity and time no facing to any shortage. Because the stations are blow by blow or in series thus if one station faces any backlog, all of former stations will be impressed and production line might be stopped. The stations are as a corridor wherever part pallets are located in both left and right sides of its station aisle as it's shown in Fig2. Each part is known with its kanban cards that determine the quantity and timing of each material feeding.

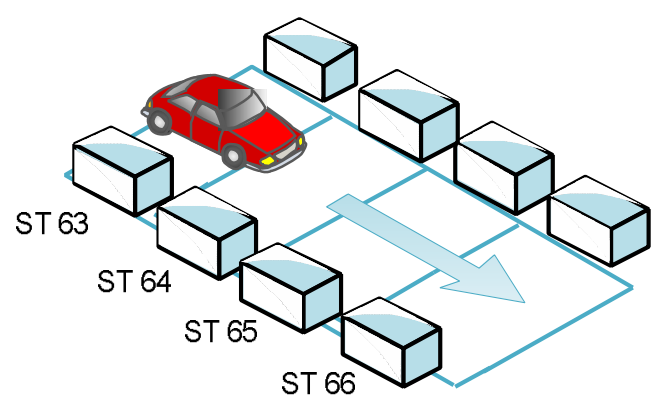

Fig 2: Racks are located in right and left hands of each station aisle 
There are two systems that a kanban can implement it in feeding procedures: Fixed-order-size (FOS) and Fixedinterval-system (FIS). The differences between two mentioned systems are not the purpose of our paper so we assume kanban cart rotation using FOS system. Kanban Cards are used as a sign that specify needs of some parts or materials. Because in many manufacturing industries such as automotive, the variety and quantity of parts can be high, lots of Cards can be released and putted in supplying status at the same time or a very small time interval. Preparing parts takes variable time related to their type, weight, quantity and etc. so we can consider the Kanban Cards as some jobs with their process time (provision time). We can consider the logistic unit as a single machine provides the requested parts signed by Kanban Cards. So we can model the kanban card rotations as a scheduling and sequencing model. To find the objective function and making some improvements, at first, we have to introduce some Kanban calculation formulas:

D: $\quad$ Tact Time Rate

T: Cycle Time (Waiting time for resupplying)

$\alpha$ : Management Coefficient

C: Standard Pallet Capacity

The number of Kanban Pallets $(\mathrm{N})$ is calculated as following:

$$
N=\frac{D \cdot T(1+\alpha)}{C}
$$

As it has shown in Formula $1, \alpha$ is a coefficient that effects on safety stock quantities and is multiplied to the cycle time. This coefficient makes the cycle time greater. It shows the important role of Cycle Time alteration in Kanban Calculations

Assume that there are many varieties and quantity of parts must be assembled together to make one unit of final product.
For example in automotive industry it can exist above two thousands of different type of parts, so it is possible to be released many kanban cards that must be resupplied in a short duration of time. It makes one sequencing and scheduling problem. Minimizing the Cycle time prevent any probable shortage in production lines. Changing the sequences of jobs (kanban Cards) can make improvement in some scheduling objective functions. We calculate the suitable number of kanban pallets considering that the lead time required to resupplying the parts are equal to $\mathrm{T} \times(1+\alpha)$. The shortage happens if the real time for resupplying the kanban takes more than $\mathrm{T} \times(1+\alpha)$. In this form, the shortages causes interruption in production line, so what is main cause of this occurrence is the tardiness of resupplying procedure. The tardiness is the difference between the real supply time and forecasted time. So if we look this problem as a scheduling model, we can consider the forecasted resupplying time $(\mathrm{T} \times(1+\alpha)$ as a due time and supplying times as process times. In this case, all kanban cards are presumed as jobs. We choose the total weighted tardiness to minimize as objective function. Because the weights and importance of each part can be different to others so we can exert a weighting method to scheduling model and alter our objective function to average weighted Flow-time. To be more clear an example has represented. To be easier, we assume all weights for this example equal to 1 . Table 1, shows the kanban cards as jobs and their sequencing parameters. Calculating the Supply Time and Due Time according to the mentioned formula in table 1 and 2 , the Tardiness would be calculated by subtracting the Supply time from the Due Time. The Positive Tardiness happens when Due time is less than the Supply Time and otherwise the Tardiness is equal to zero. Shortages caused by the tardiness are related to the Tact Time Rate and its quantity equals the Tardiness value multiplied by Tact Time Rate.

Table 1. Example 1, Kanban cards and scheduling parameters information in original sequence

\begin{tabular}{|c|c|c|c|c|c|c|}
\hline $\begin{array}{c}\text { Kanban } \\
\text { released }\end{array}$ & Part numbers & Part Names & $\begin{array}{c}\text { Supply Time } \\
(\text { Min) }\end{array}$ & $\begin{array}{c}\text { Due Time }= \\
\mathrm{T} \times(1+\alpha)\end{array}$ & Tardiness & Shortages \\
\hline 1 & $00042681940 \mathrm{E}$ & bracket & 7 & 6 & 1 & $\mathrm{D}$ \\
\hline 2 & $00077043860 \mathrm{E}$ & lock & 12 & 19 & 0 & 0 \\
\hline 3 & $00464491910 \mathrm{E}$ & Clip & 3 & 21 & 1 & $\mathrm{D}$ \\
\hline 4 & $00824568640 \mathrm{E}$ & Insulation & 5 & 45 & 0 & 0 \\
\hline 5 & $00500001610 \mathrm{E}$ & Screw & 20 & 42 & 5 & $5 \mathrm{D}$ \\
\hline
\end{tabular}

As it has shown in Table 1, if the released kanban are resupplied via 1 worker, we can see 7 minutes of tardiness as resupplying time or 7.D units of shortages. Now we change the sequencing of jobs via changing the sequence of $4^{\text {th }}$ and $5^{\text {th }}$ kanban card.

Table 2. Example 1, Kanban cards and scheduling parameters information in custom sequence

\begin{tabular}{|c|c|c|c|c|c|c|}
\hline $\begin{array}{c}\text { Kanban } \\
\text { released }\end{array}$ & Part numbers & Part Names & $\begin{array}{c}\text { Supply Time } \\
(\text { Min })\end{array}$ & $\begin{array}{c}\text { Due Time }= \\
\mathrm{T} \times(1+\alpha)\end{array}$ & Tardiness & Shortages \\
\hline 1 & $00042681940 \mathrm{E}$ & bracket & 7 & 6 & 1 & $\mathrm{D}$ \\
\hline 2 & $00077043860 \mathrm{E}$ & lock & 12 & 19 & 0 & 0 \\
\hline 3 & $00464491910 \mathrm{E}$ & Clip & 3 & 21 & 1 & $\mathrm{D}$ \\
\hline 5 & $00500001610 \mathrm{E}$ & Screw & 20 & 42 & 0 & 0 \\
\hline 4 & $00824568640 \mathrm{E}$ & Insulation & 5 & 45 & 2 & $2 \mathrm{D}$ \\
\hline
\end{tabular}

As the new result from custom sequence of jobs we found in new sequence of jobs, we have only 4 unit of time as tardiness so we made 3.D unit of thriftiness in shortages. It shows that if we continue to rearrange the jobs we can be hopeful more diminishing in shortages and tardiness. The comparison between completion time and due date for each Card has shown in Fig 3 and Fig 4. 


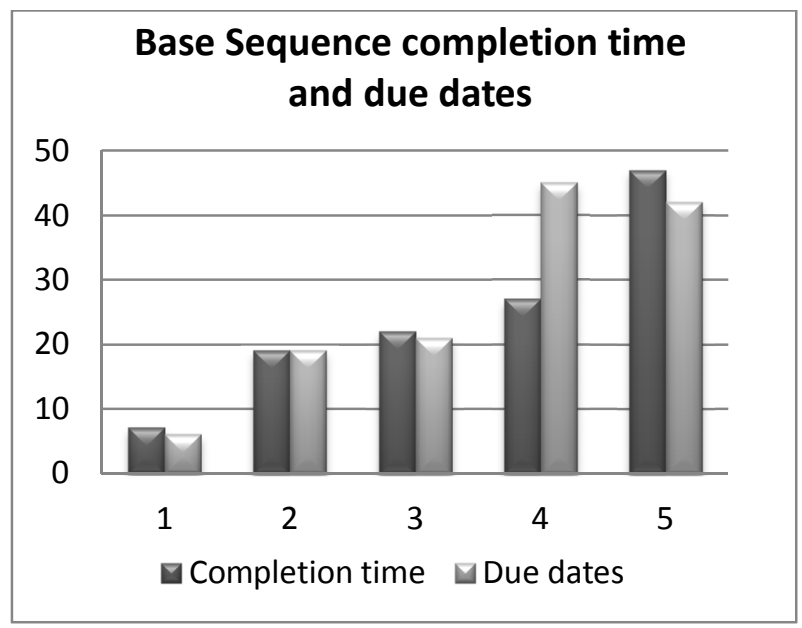

Fig 3: Primary Sequence Completion time and due dates

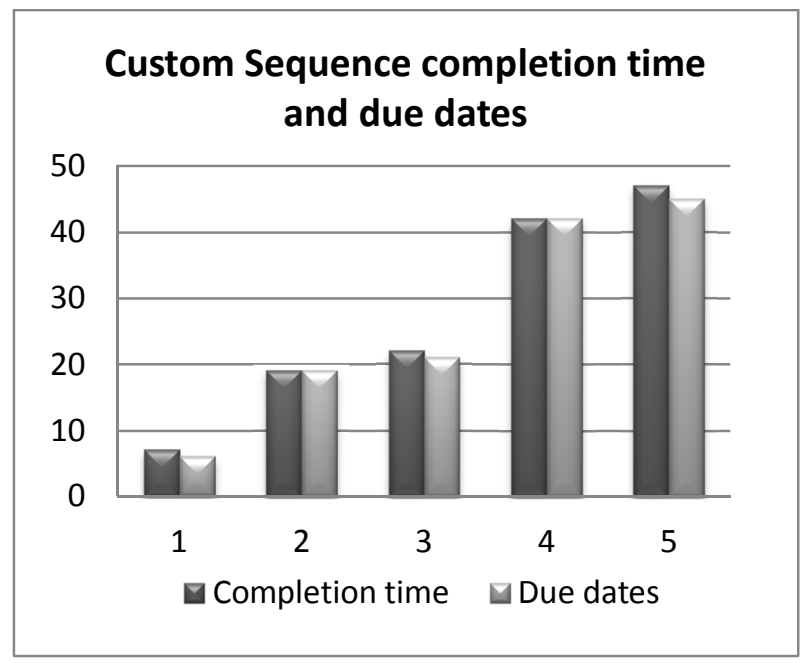

Fig 4: Custom Sequence Completion time and due dates

\section{WEIGHT CALCULATION}

As we mentioned in last part, the emphasis of each job is not equal so they have different types of weight thus we should calculate the weights for alternatives to use them as Tardiness Weights. In decision making techniques, we usually calculate the weights of criteria and according to the yielded weights; we sort the alternatives and make new decision. In this problem, we need the importance of each order that is our alternative. We mix Shannon's Entropy weighting method with SAW technique to calculate the appropriate weights. Each kanban card can be different to another within some criteria such requirement urgency, weight and etc.

Table 3. Decision Making Matrix

\begin{tabular}{|c|c|c|c|c|}
\hline DM MATRIX & Criterion 1 & Criterion 2 & $\ldots$ & Criterion $\mathrm{n}$ \\
\hline Alt 1 & $\mathrm{x}_{11}$ & $\mathrm{x}_{12}$ & $\ldots$ & $\mathrm{x}_{1 \mathrm{n}}$ \\
\hline Alt 2 & $\mathrm{x}_{21}$ & $\mathrm{x}_{22}$ & $\ldots$ & $\mathrm{x}_{2 \mathrm{n}}$ \\
\hline$\vdots$ & $\vdots$ & $\vdots$ & $\vdots$ & $\mathrm{x}_{\mathrm{n} 1}$ \\
\hline Alt $\mathrm{m}$ & $\mathrm{x}_{\mathrm{m} 1}$ & $\mathrm{x}_{\mathrm{m} 2}$ & $\ldots$ & $\mathrm{x}_{\mathrm{mn}}$ \\
\hline weights & $\mathrm{w}_{1}$ & $\mathrm{w}_{2}$ & $\ldots$ & $\mathrm{w}_{\mathrm{n}}$ \\
\hline
\end{tabular}

To calculate the weights for each item, it should be followed at following formulas and procedure: a. Normalize the decision matrix like following formula

Set $p_{i j}=\frac{x_{i j}}{\sum_{i=1}^{m} x_{i j}} \quad j=1, \ldots, n, \quad i=1, \ldots, m$

b. Compute entropy $h_{j} \quad$ as $\quad h_{j}=-h_{0} \sum_{i=1}^{m} p_{i j} \cdot \ln p_{i j}$

Where $h_{0}$ is the entropy constant and is equal to ( $\left.\operatorname{Ln} m\right)^{-1}$ and $p_{i j} \cdot \ln p_{i j}$ is defined as 0 if $p_{i j}=0$.

c. Set $d_{j}=1-h_{j}, j=1, \ldots, n$ as the degree of diversification.

d. Set $w_{j}=\frac{d_{j}}{\sum_{s=1}^{n} d_{s}}, j=1, \ldots, n \quad$ as the degree of importance of attribute $i$.

e. The values for all alternatives can be calculated as follow:

$A_{i}=\sum_{j=1}^{n} w_{j} \cdot x_{i j}$

f. All the weights for alternatives can be calculated as next formula:

$w_{i}=\frac{A_{i}}{\sum_{i=1}^{m} A_{i}}$

\section{CASE STUDY}

To apply our method to a real world case study, we study the BonroCo Automotive Factory production line that produces Fiat Siena. BonroCo is a company in southern countryside part of Saveh City in Iran. It is located 7 kilometers far from the central part of the city. This company makes the Fiat Cars; just Siena model within a process includes 99 production line stations. The painted body entered to station 1 in trim-line and the parts are assembled to the main body and the cars are being completed gradually and exeunt the last station. The parts are carried from Fiat Company in Italy and Tofas Company in Turkey to Saveh in cases. The cases are kept and maintained in warehouse and are waited until the unpack list is issued. When the unpack list is prepared, all the parts required are identified in cases and are carried to the Unpack Unit. After unpacking the cases, the parts are labeled and counted and are placed in appropriate pallets and are put to Logistic Area racks by supply-feeding unit. This unit receives the parts and organizes them in their predefined locations and waits for part requests. Part requests, are the released kanban cart put in supply-box.

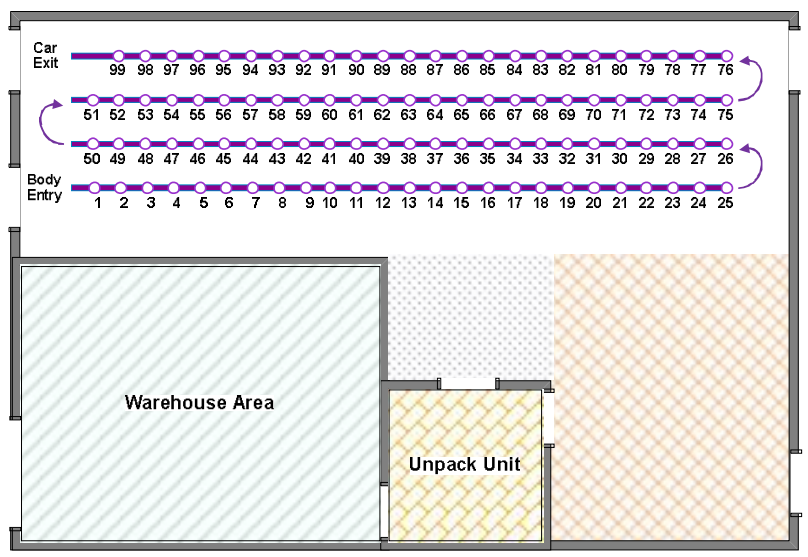


There are 4 teams with 3 members that have responsibility of supplying and feeding the parts to the stations according the Kanban System. One team for massive parts are just carried by lift trucks and three teams for other parts could be carried easily. The supply-Logistic Layout has shown in Fig 5.

The problem is that, in one moment or a little period of time, there are several released Kanban cards must be resupplied. As we mentioned former, we have 4 groups numbered 1 to 4 , 3 people in groups that each group could only supply maximum 5 Card at one time. Group 4 is used just for massive parts needs lift truck to carry. Kanban cards are distributed to groups according to their size and weight. Finally there will be some Cards must resupplied in each group. As we mentioned in section 2 we saw that lateness in resupplying time increases the estimated standard resupplying time was equal to $\mathrm{T} \times(1+\alpha)$ which leads to shortage in production line. So what we are going to do is minimizing the lateness of resupplying procedure using sequencing and scheduling method. On other hand, we want to show, changing the sequences of works leads to less average tardiness causes shortages.

We tried to collect the required data to show the result. We chose 40 samples of data of different days in two weeks. The weights are calculated by formula presented in section 3 , and we used the VNS algorithms to solve the Total Weighted Tardiness objective function. We programmed the VNS algorithm and put our data as input and obtained the results.it this case we assume all weights equal to 1 .

Table 4. Kanban cards and scheduling parameters information in primary sequence for group 1

\begin{tabular}{|c|c|c|c|c|c|c|c|c|}
\hline \multicolumn{9}{|c|}{ Cards Allocated to Group 1} \\
\hline $\begin{array}{l}\text { Kanban } \\
\text { released }\end{array}$ & Pic & Part Numbers & Station & Part Names & $\begin{array}{l}\text { Supply Time } \\
\text { (Min) }\end{array}$ & $\begin{array}{l}\text { Due Time }= \\
\mathrm{T} \times(1+\alpha)\end{array}$ & Tardiness & Shortages \\
\hline F0042 & & $00130461110 \mathrm{E}$ & $3 \mathrm{RH}$ & NUT M6 & 7 & 16 & 0 & 0 \\
\hline F0501 & & $00130971900 \mathrm{E}$ & $51 \mathrm{LH}$ & COLLAR & 8 & 19 & 0 & 0 \\
\hline F1052 & & $07353027430 \mathrm{E}$ & $23 \mathrm{LH}$ & MIRROR LT & 3 & 23 & 0 & 0 \\
\hline F1559 & & $07354487590 \mathrm{E}$ & $65 \mathrm{RH}$ & LOGO & 5 & 18 & 4 & 4D \\
\hline F0996 & & $00517144960 \mathrm{E}$ & $10 \mathrm{LH}$ & $\begin{array}{c}\text { ABSORBER } \\
\text { BUSHING }\end{array}$ & 7 & 14 & 15 & 15D \\
\hline
\end{tabular}

In primary sequences of cards like F0042, F0501, F1052,F4559 and F0996, the total tardiness is equal to 19 thus total shortages in this sequence will be equal to 19D.After running the VNS by our computer program, the new sequencing has obtained with minimum total tardiness, F0042, F0996, F1559, F1052 and F0501. Results have shown in Table 5.

Table 5. Optimal sequences of cards with minimum total tardiness for group 1

\begin{tabular}{|c|c|c|c|c|c|c|c|}
\hline \multicolumn{7}{|c|}{ Cards Allocated to Group 1 } \\
\hline $\begin{array}{c}\text { Kanban } \\
\text { released }\end{array}$ & Part Numbers & Station & Part Names & $\begin{array}{c}\text { Supply Time } \\
(\text { Min })\end{array}$ & $\begin{array}{c}\text { Due Time }= \\
\text { T } \times(1+\alpha)\end{array}$ & Tardiness & Shortages \\
\hline F0042 & $00130461110 \mathrm{E}$ & $3 \mathrm{RH}$ & NUT M6 & 7 & 16 & 0 & 0 \\
\hline F0996 & $00517144960 \mathrm{E}$ & $10 \mathrm{LH}$ & ABSORBER BUSHING & 7 & 14 & 0 & 0 \\
\hline F1559 & $07354487590 \mathrm{E}$ & $65 \mathrm{RH}$ & LOGO & 5 & 18 & 1 & D \\
\hline F1052 & $07353027430 \mathrm{E}$ & $23 \mathrm{LH}$ & MIRROR LT & 3 & 23 & 0 & 0 \\
\hline F0501 & $00130971900 \mathrm{E}$ & $51 \mathrm{LH}$ & COLLAR & 8 & 19 & 11 & $11 \mathrm{D}$ \\
\hline
\end{tabular}

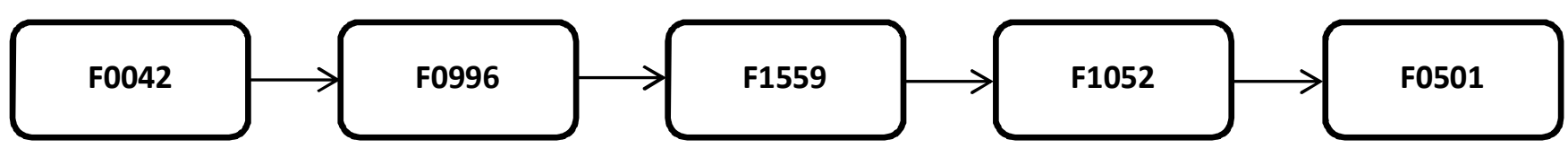

Fig 6: Optimal Sequences of orders

As we see, the new sequences of Cards made 8 unit diminutions in total tardiness make $8 \mathrm{D}$ unit diminutions in shortages. If we change this optimal sequence of Cards, total tardiness will increase anyway. You can see the optimal 
sequences of Cards in Fig 6. Because for group $2 \& 3$ we have the same method we only bring their results at final part, but because group 4 is for massive parts, so we will present the
Cards and the sequencing result in Table 5 and Table 6 like we presented for group1.

Table 6. Kanban cards and scheduling parameters information in primary sequence for group 4

\begin{tabular}{|c|c|c|c|c|c|c|c|c|}
\hline \multicolumn{9}{|c|}{ Cards Allocated to Group 4} \\
\hline $\begin{array}{l}\text { Kanban } \\
\text { released }\end{array}$ & Pic & Part Numbers & Station & Part Names & $\begin{array}{l}\text { Supply Time } \\
\text { (Min) }\end{array}$ & $\begin{array}{l}\text { Due Time }= \\
\mathrm{T} \times(1+\alpha)\end{array}$ & Tardiness & Shortages \\
\hline F1197 & & $00517386620 \mathrm{E}$ & $77 \mathrm{RH}$ & $\begin{array}{l}\text { HEATED REAR } \\
\text { WINDOW }\end{array}$ & 16 & 36 & 0 & 0 \\
\hline F1135 & & $07354079590 \mathrm{E}$ & $83 \mathrm{LH}$ & REAR SEAT & 14 & 41 & 0 & 0 \\
\hline F1039 & & $00517377230 \mathrm{E}$ & $22 \mathrm{RH}$ & RR. LAMP & 20 & 49 & 1 & $\mathrm{D}$ \\
\hline F1175 & & $00517921180 \mathrm{E}$ & $70 \mathrm{LH}$ & $\begin{array}{l}\text { COMPLETE } \\
\text { TYRE }\end{array}$ & 12 & 48 & 14 & $14 \mathrm{D}$ \\
\hline F1090 & & $07354082640 \mathrm{E}$ & $86 \mathrm{RH}$ & $\begin{array}{l}\text { RR. RT. DOOR } \\
\text { PANEL }\end{array}$ & 15 & 46 & 31 & $31 \mathrm{D}$ \\
\hline
\end{tabular}

In basic and primary sequences of Cards like F1197, F1135, F1039, F1175and F1090, the total tardiness is equal to 45 thus total shortages in this sequence will be equal to 45D.After rerunning the VNS, the new result with minimum total tardiness, F1135, F1197, F1090, F1175and F1039. Results have shown in Table 7 and changing the sequences of Cards will diminish total tardiness to 37 so the shortages will decrease within 8D units. Table 7 show the sequencing of Cards and calculation results after optimization.

Table 7. Optimal sequences of Cards with minimum total tardiness for group 4

\begin{tabular}{|c|c|c|c|c|c|c|c|}
\hline \multicolumn{2}{|c|}{ Cards Allocated to Group 4 } \\
\hline $\begin{array}{c}\text { Kanban } \\
\text { released }\end{array}$ & Part Numbers & Station & Part Names & $\begin{array}{c}\text { Supply Time } \\
(\text { Min })\end{array}$ & $\begin{array}{c}\text { Due Time }= \\
\text { T } \times(1+\alpha)\end{array}$ & Tardiness & Shortages \\
\hline F1135 & $07354079590 \mathrm{E}$ & $83 \mathrm{LH}$ & REAR SEAT & 14 & 41 & 0 & 0 \\
\hline F1197 & $00517386620 \mathrm{E}$ & $77 \mathrm{RH}$ & HEATED REAR WINDOW & 16 & 36 & 0 & 0 \\
\hline F1090 & $07354082640 \mathrm{E}$ & $86 \mathrm{RH}$ & RR. RT. DOOR PANEL & 15 & 46 & 0 & 0 \\
\hline F1175 & $00517921180 \mathrm{E}$ & $70 \mathrm{LH}$ & COMPLETE TYRE & 12 & 48 & 9 & $9 \mathrm{D}$ \\
\hline F1039 & $00517377230 \mathrm{E}$ & $22 \mathrm{RH}$ & RR. LAMP & 20 & 49 & 28 & $28 \mathrm{D}$ \\
\hline
\end{tabular}

We chose 40 samples of data in different days. Each sample is related to one group and we tried to gather 4 samples, one for each group, in a day, so we have the data in a period of time in each day for all groups. We ran our Computer program on all samples of data and calculated the total tardiness and total reduction of shortage per group. Total tardiness calculated in both primary and optimal sequencing of all 40 samples is available in Fig 7.

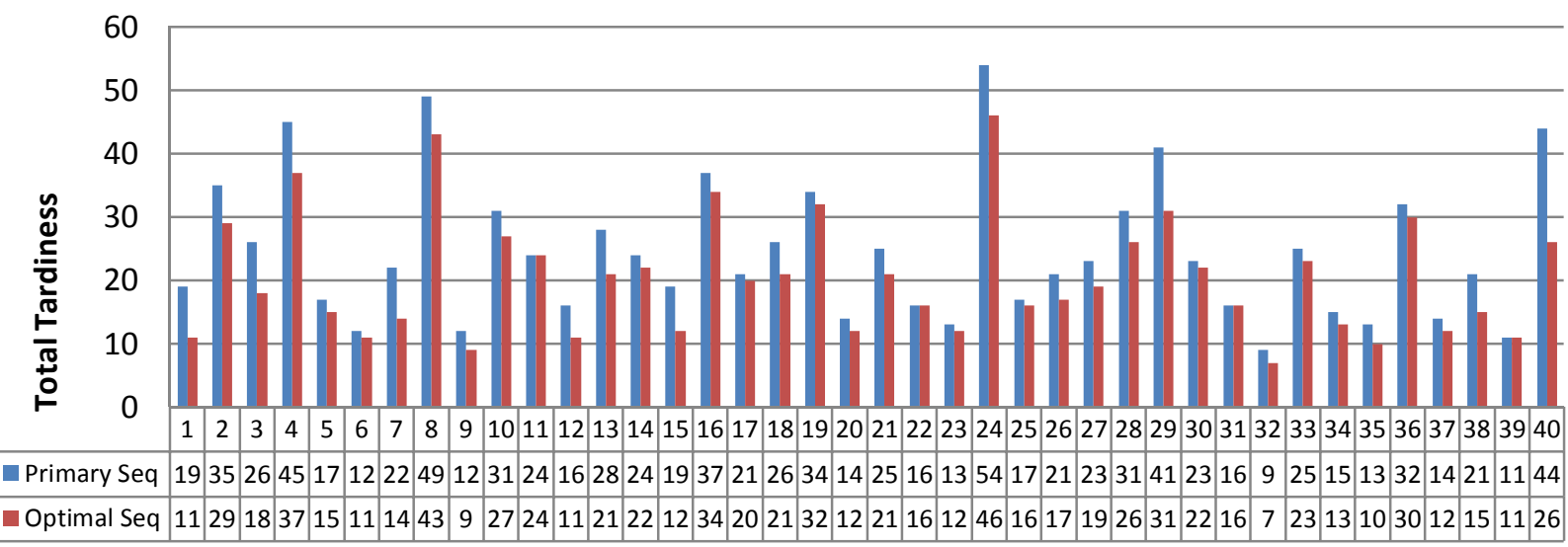

Fig 7: Total Tardiness Calculated in Primary and Optimal Sequence of Cards 
Table 8. Tardiness Reduction Percent due to changing sequences of Cards, using VNS programming

\begin{tabular}{|c|c|c|c|c|c|c|c|c|}
\hline \multicolumn{2}{|c|}{ Day } & \multirow{2}{*}{$\frac{\text { Group }}{1}$} & \multicolumn{5}{|c|}{ Part Numbers } & \multirow{2}{*}{$\begin{array}{c}\text { \%Tardiness } \\
\text { Reduction }\end{array}$} \\
\hline \multirow{4}{*}{1} & \multirow{4}{*}{$\stackrel{\overrightarrow{0}}{\mathscr{n}}$} & & $00130461110 \mathrm{E}$ & $00130971900 \mathrm{E}$ & $07353027430 \mathrm{E}$ & $07354487590 \mathrm{E}$ & $00517144960 \mathrm{E}$ & \\
\hline & & 2 & $00044465460 \mathrm{E}$ & $00467815390 \mathrm{E}$ & $00076226060 \mathrm{E}$ & $00156878010 \mathrm{E}$ & $00076352330 \mathrm{E}$ & 17.1 \\
\hline & & 3 & $00076877080 \mathrm{E}$ & $00988122200 \mathrm{E}$ & 00464016570E & 00988124920E & $00141441910 \mathrm{E}$ & 30.8 \\
\hline & & 4 & $00517386620 \mathrm{E}$ & $07354079590 \mathrm{E}$ & $00517377230 \mathrm{E}$ & $00988228680 \mathrm{E}$ & $07354082640 \mathrm{E}$ & 17.8 \\
\hline \multirow{4}{*}{2} & \multirow{4}{*}{$\stackrel{\Xi}{\Xi}$} & 1 & $00144964010 \mathrm{E}$ & $00145084870 \mathrm{E}$ & $00145602870 \mathrm{E}$ & $00143085240 \mathrm{E}$ & $00464093170 \mathrm{E}$ & 11.8 \\
\hline & & 2 & $00464231210 \mathrm{E}$ & $00464205180 \mathrm{E}$ & $00464190760 \mathrm{E}$ & $00464187470 \mathrm{E}$ & $00162871210 \mathrm{E}$ & 8.3 \\
\hline & & 3 & $00464176830 \mathrm{E}$ & $00464183800 \mathrm{E}$ & $00464281570 \mathrm{E}$ & $00464227650 \mathrm{E}$ & $00464345840 \mathrm{E}$ & 36.4 \\
\hline & & 4 & $00464190360 \mathrm{E}$ & $00518209760 \mathrm{E}$ & $00517386350 \mathrm{E}$ & $00517377220 \mathrm{E}$ & $00551864410 \mathrm{E}$ & 12.2 \\
\hline \multirow{4}{*}{3} & \multirow{4}{*}{$\sum^{0}$} & 1 & $00464255700 \mathrm{E}$ & $00464359470 \mathrm{E}$ & $00146313870 \mathrm{E}$ & $00077463090 \mathrm{E}$ & $00464093050 \mathrm{E}$ & 25.0 \\
\hline & & 2 & $00464598700 \mathrm{E}$ & $00517232640 \mathrm{E}$ & $00104457210 \mathrm{E}$ & $00517502080 \mathrm{E}$ & $00465491140 \mathrm{E}$ & 12.9 \\
\hline & & 3 & $00077398010 \mathrm{E}$ & $00075685870 \mathrm{E}$ & $00467847660 \mathrm{E}$ & $00111907740 \mathrm{E}$ & $00467366100 \mathrm{E}$ & 0 \\
\hline & & 4 & $07352878000 \mathrm{E}$ & $07353973680 \mathrm{E}$ & $00988143940 \mathrm{E}$ & $00467903990 \mathrm{E}$ & $00464152100 \mathrm{E}$ & 31.3 \\
\hline \multirow{4}{*}{4} & \multirow{4}{*}{$\stackrel{\varrho}{\Theta}$} & 1 & $00126425240 \mathrm{E}$ & $00551961910 \mathrm{E}$ & $00517200700 \mathrm{E}$ & $00551999590 \mathrm{E}$ & $00157834070 \mathrm{E}$ & 25.0 \\
\hline & & 2 & $00467827310 \mathrm{E}$ & $00517075810 \mathrm{E}$ & $00517821880 \mathrm{E}$ & $00077967930 \mathrm{E}$ & $00468301490 \mathrm{E}$ & 8.3 \\
\hline & & 3 & $00465367330 \mathrm{E}$ & $00465328550 \mathrm{E}$ & $00126378040 \mathrm{E}$ & $00116124240 \mathrm{E}$ & $00551824600 \mathrm{E}$ & 36.8 \\
\hline & & 4 & $00467922750 \mathrm{E}$ & $00517712250 \mathrm{E}$ & $00464108540 \mathrm{E}$ & $07352961590 \mathrm{E}$ & $07353757200 \mathrm{E}$ & 8.1 \\
\hline \multirow{4}{*}{5} & \multirow{4}{*}{$\frac{\bar{d}}{3}$} & 1 & $00517029910 \mathrm{E}$ & $00467640500 \mathrm{E}$ & $00988126180 \mathrm{E}$ & $00517556960 \mathrm{E}$ & $00605766400 \mathrm{E}$ & 4.8 \\
\hline & & 2 & $00126471240 \mathrm{E}$ & $00464169600 \mathrm{E}$ & $00517868300 \mathrm{E}$ & $00044465460 \mathrm{E}$ & $00111094900 \mathrm{E}$ & 19.2 \\
\hline & & 3 & $00518087000 \mathrm{E}$ & $00076478050 \mathrm{E}$ & $00464804510 \mathrm{E}$ & $00009949220 \mathrm{E}$ & $00468346280 \mathrm{E}$ & 5.9 \\
\hline & & 4 & $00468470560 \mathrm{E}$ & $07353005820 \mathrm{E}$ & $00517200700 \mathrm{E}$ & $910 \mathrm{E}$ & $00077323540 \mathrm{E}$ & 14.3 \\
\hline \multirow{4}{*}{6} & \multirow{4}{*}{ 莺 } & 1 & $00467597100 \mathrm{E}$ & $00517712250 \mathrm{E}$ & $00517522420 \mathrm{E}$ & $00464108540 \mathrm{E}$ & $00517712250 \mathrm{E}$ & 16.0 \\
\hline & & 2 & $00468272540 \mathrm{E}$ & $00517747390 \mathrm{E}$ & $00140594110 \mathrm{E}$ & $07353597940 \mathrm{E}$ & $00517721900 \mathrm{E}$ & 0 \\
\hline & & 3 & $00551816320 \mathrm{E}$ & $07353615670 \mathrm{E}$ & $00988221290 \mathrm{E}$ & $00162861240 \mathrm{E}$ & $07353606700 \mathrm{E}$ & 7.7 \\
\hline & & 4 & $00077323540 \mathrm{E}$ & $07353627400 \mathrm{E}$ & $00517915230 \mathrm{E}$ & $00464363860 \mathrm{E}$ & $07354050040 \mathrm{E}$ & 14.8 \\
\hline \multirow{4}{*}{7} & \multirow{4}{*}{$\stackrel{\Xi}{\Xi}$} & 1 & $00467586290 \mathrm{E}$ & $00077140650 \mathrm{E}$ & $07353164690 \mathrm{E}$ & $00465446620 \mathrm{E}$ & $00077648220 \mathrm{E}$ & 5.9 \\
\hline & & 2 & $00518044880 \mathrm{E}$ & $00517627560 \mathrm{E}$ & $07353999070 \mathrm{E}$ & $00077408820 \mathrm{E}$ & $00468173740 \mathrm{E}$ & 19.0 \\
\hline & & 3 & $00517160650 \mathrm{E}$ & $00138374140 \mathrm{E}$ & $00517356170 \mathrm{E}$ & $00467584270 \mathrm{E}$ & $00076766140 \mathrm{E}$ & 17.4 \\
\hline & & 4 & $07354088530 \mathrm{E}$ & $00464469110 \mathrm{E}$ & $07353982520 \mathrm{E}$ & $07354081910 \mathrm{E}$ & $00468373170 \mathrm{E}$ & 16.1 \\
\hline \multirow{4}{*}{8} & \multirow{4}{*}{$\stackrel{\Xi}{\Sigma}$} & 1 & $00467632630 \mathrm{E}$ & $00517747380 \mathrm{E}$ & $00077223760 \mathrm{E}$ & $00464304740 \mathrm{E}$ & $00076003910 \mathrm{E}$ & 24.4 \\
\hline & & 2 & $00464445650 \mathrm{E}$ & $00465162090 \mathrm{E}$ & $00126544210 \mathrm{E}$ & $00464443730 \mathrm{E}$ & $00606070240 \mathrm{E}$ & 4.3 \\
\hline & & 3 & $07353627400 \mathrm{E}$ & $00075149210 \mathrm{E}$ & $00464345840 \mathrm{E}$ & $00146476900 \mathrm{E}$ & $00468131690 \mathrm{E}$ & 0 \\
\hline & & 4 & $00517515240 \mathrm{E}$ & $07354016980 \mathrm{E}$ & $07353973650 \mathrm{E}$ & $00551864410 \mathrm{E}$ & $00076874260 \mathrm{E}$ & 22.2 \\
\hline \multirow{4}{*}{9} & \multirow{4}{*}{$\stackrel{g}{\Xi}$} & 1 & $00517159930 \mathrm{E}$ & $00468129900 \mathrm{E}$ & $00115684240 \mathrm{E}$ & $00517747520 \mathrm{E}$ & $00141441910 \mathrm{E}$ & 8.0 \\
\hline & & 2 & $00464721260 \mathrm{E}$ & $07353981410 \mathrm{E}$ & $00125740110 \mathrm{E}$ & $00076478750 \mathrm{E}$ & $00161008150 \mathrm{E}$ & 13.3 \\
\hline & & 3 & $00467906980 \mathrm{E}$ & $00518237870 \mathrm{E}$ & $00140396110 \mathrm{E}$ & $00824910460 \mathrm{E}$ & $00467922740 \mathrm{E}$ & 23.1 \\
\hline & & 4 & $07354050680 \mathrm{E}$ & $00467467570 \mathrm{E}$ & $07179538010 \mathrm{E}$ & $00517473180 \mathrm{E}$ & $07354418810 \mathrm{E}$ & 6.3 \\
\hline \multirow{4}{*}{10} & \multirow{4}{*}{$\frac{\pi}{3}$} & 1 & $00988124930 \mathrm{E}$ & $00467430340 \mathrm{E}$ & $00517747480 \mathrm{E}$ & $00141158850 \mathrm{E}$ & $00076226060 \mathrm{E}$ & 14.3 \\
\hline & & 2 & $07179548010 \mathrm{E}$ & $00138321010 \mathrm{E}$ & $00468478460 \mathrm{E}$ & $07353757200 \mathrm{E}$ & $00142154800 \mathrm{E}$ & 28.6 \\
\hline & & 3 & $00126477040 \mathrm{E}$ & $00468330760 \mathrm{E}$ & $00464755830 \mathrm{E}$ & $00145740800 \mathrm{E}$ & $00517515270 \mathrm{E}$ & 0 \\
\hline & & 4 & $07353608510 \mathrm{E}$ & $00467647400 \mathrm{E}$ & $00988143940 \mathrm{E}$ & $07354088860 \mathrm{E}$ & $00468186010 \mathrm{E}$ & 40.9 \\
\hline
\end{tabular}

Table 8, shows the Tardiness Calculations and Tardiness Reduction Percentage. As it has shown in Table 8, tardiness reduction of each sample of data has calculated. Using the Data Input Analyzer Software, the tardiness reductions are fitted to Triangular distribution with parameters 0, 5.78 and 43 separately. Chi Square and Kolmogorov-Smirnov Tests results are as following:

Table 9. Input Analyzer Results

\begin{tabular}{|lc|lc|}
\hline \multicolumn{2}{|c|}{ Chi Square Test } & \multicolumn{1}{c|}{ Kolmogorov-Smirnov Test } \\
\hline Number of intervals & $=5$ & Test Statistic & $=0.0773$ \\
Degrees of freedom & $=3$ & Corresponding p-value & $>0.15$ \\
Test Statistic & $=0.459$ & & \\
Corresponding p-value & $>0.75$ & & \\
\hline
\end{tabular}

The mean and standard deviation of distribution are 16.26 and 11.29 respectively that means changes in primary sequences of Kanban Cart resupplying could cause improvement in quantity of possible shortages. The histogram of tardiness reductions figured by Minitab has shown in Fig 8. 


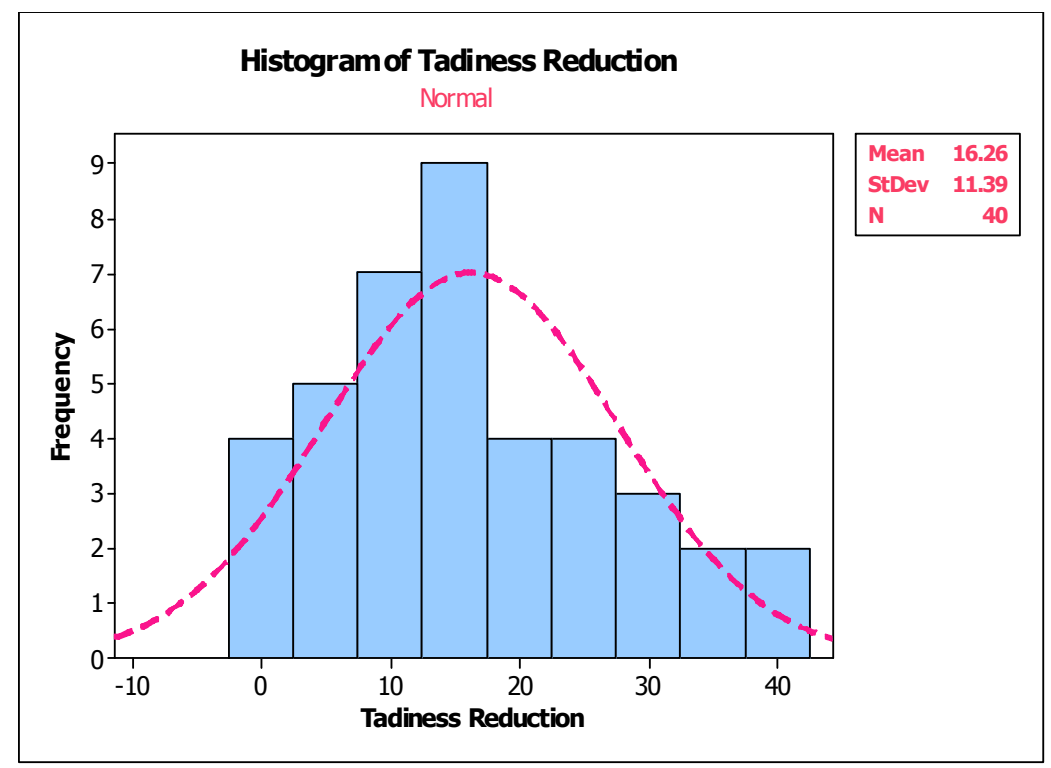

Fig 8: Histogram of Tardiness Reduction

According to this triangular distribution we can find that the tardiness reductions have positive skewness that means most tardiness reductions are less than the mean. Anyway, we can assume average shortage reductions for all parts will be calculated by the Master Production Schedule quantities multiplied by the Tardiness Reduction Percent has brought about in table 8 . The MPS for 10 sampling days has shown in Table 10.Considering "\% Tardiness Reduction" field of Table 8 and MPS quantities of Table 10, total shortage for all items is calculated as follows:

Table 10. MPS quantities for the 10 sampling days and shortage reduction calculations

\begin{tabular}{|c|c|c|c|c|c|c|c|}
\hline $\begin{array}{l}\text { Week } \\
\text { Days }\end{array}$ & Group & Day & $\begin{array}{l}\text { MPS } \\
\text { quantity }\end{array}$ & $\begin{array}{l}\text { MPS quantity } \\
\times \\
\% \text { Tardiness } \\
\text { Reduction }\end{array}$ & Day & $\begin{array}{l}\text { MPS } \\
\text { quantity }\end{array}$ & $\begin{array}{l}\text { MPS quantity } \\
\times \\
\% \text { Tardiness } \\
\text { Reduction }\end{array}$ \\
\hline \multirow{4}{*}{$\underset{\tilde{N}}{\tilde{E}}$} & 1 & \multirow{4}{*}{1} & \multirow{4}{*}{32} & 14 & \multirow{4}{*}{6} & \multirow{4}{*}{28} & 5 \\
\hline & 2 & & & 6 & & & 0 \\
\hline & 3 & & & 10 & & & 3 \\
\hline & 4 & & & 6 & & & 5 \\
\hline \multirow{4}{*}{$\underset{\mathscr{S}}{\Xi}$} & 1 & \multirow{4}{*}{2} & \multirow{4}{*}{32} & 4 & \multirow{4}{*}{7} & \multirow{4}{*}{28} & 2 \\
\hline & 2 & & & 3 & & & 6 \\
\hline & 3 & & & 12 & & & 5 \\
\hline & 4 & & & 4 & & & 5 \\
\hline \multirow{4}{*}{$\stackrel{0}{\Sigma}$} & 1 & \multirow{4}{*}{3} & \multirow{4}{*}{30} & 8 & \multirow{4}{*}{8} & \multirow{4}{*}{28} & 7 \\
\hline & 2 & & & 4 & & & 2 \\
\hline & 3 & & & 0 & & & 0 \\
\hline & 4 & & & 10 & & & 7 \\
\hline \multirow{4}{*}{$\stackrel{\varrho}{\rightleftarrows}$} & 1 & \multirow{4}{*}{4} & \multirow{4}{*}{30} & 7 & \multirow{4}{*}{9} & \multirow{4}{*}{30} & 3 \\
\hline & 2 & & & 3 & & & 4 \\
\hline & 3 & & & 11 & & & 7 \\
\hline & 4 & & & 3 & & & 2 \\
\hline \multirow{4}{*}{$\vec{B}_{3}^{0}$} & 1 & \multirow{4}{*}{5} & \multirow{4}{*}{28} & 2 & \multirow{4}{*}{10} & \multirow{4}{*}{32} & 5 \\
\hline & 2 & & & 6 & & & 10 \\
\hline & 3 & & & 2 & & & 0 \\
\hline & 4 & & & 4 & & & 14 \\
\hline \multicolumn{7}{|c|}{ Total Shortage Reduction } & 211 \\
\hline
\end{tabular}




\section{CONCLUSION AND FUTURE STUDY}

Nowadays, changing the production system from Make-tostock to Make-to-order is very vital in all industries. In order to achieve the JIT concepts, Kanban is a pull system that is very familiar in industries especially automotive industry. Changing the sequencing and scheduling of Kanban Cards make some new attribute alteration for Logistic Systems. So we tried to show the effect of this matter on possible shortages may happen in a pull system. We chose the total tardiness objective function to solve our model and find the effect of the sequence alteration in total tardiness of Cards and shortages.in this article we only studied the Kanban in Logistic Systems while it is possible to assess the Kanban in all supply chain starts from suppliers and ends to customers. In future we can study another pull and push systems and apply the scheduling specifications on them and also we can evaluate Kanban in all supply chain include manufacturing, customers and suppliers.

\section{Acknowledgement}

The authors are grateful to the reviewers for their useful suggestions, highly contributed to improve the value of the paper.

\section{REFERENCES}

[1] Gravel, M., and Price, W.L. 1988. Using the kanban in a job shop environment. International journal of production research, 26(6), 1105-1118.

[2] Framinan, J.M., Gonzalez, P.L. and Ruiz-Usano, R. 2006. Dynamic card controlling in a CONWIP systems. International Journal of Production Economics, 99, 102116.

[3] Pettersena, J.A., and Segerstedt, A.(2009). Restricted work-in-process: A study of differences between Kanban and CONWIP. International Journal of Production Economics. 118(1)(199-207).

[4] Junior, M.L., and Fulho, M.G. 2010. Variations of the kanban systems: Literature review and Classification. International journal of Production Economics, 125 (2010) 13-21.

[5] Sipper, D., and Bulfin, R.L. 1997. Production : Planning, Control and Integration. Mcgraw-Hill, New Yourk.

[6] Rabbani, M., Layegh, J., and Mohammad, Ebrahim, R.(2009). Determination of number of kanbans in a supply chain system via Memetic algorithm. Advances in Engineering Software. 40(6)(431-437).

[7] Tardif, V., and Maaseidvaag, L. 2001. An adaptive approach to controlling kanban systems. European Journal of Operational Research, 132(2), 411-424.

[8] Chaudhury, A., and Whinston, A.B. 1990. Towords an adaptive kanban system. International Journal of Production Research. 28(3), 437-458.

[9] Yang, L., and Zhang, X.P.2009. Design and pplication of Kanban Control System in a Multi-Stage, Mixed-Model Assembly Line. Systems Engineering - Theory \& Practice. 29(9)(64-72).

[10] Mohanty, R.P., Kumar, S.,and Tiwari M.k. 2003 . Expert enhanced colourd fuzzy petri net models of traditional, flexible and reconfigurable kanban systems. Production Planning and Control 14(5), 459-477.
[11] Andijani, A.1998. A multi-criterion approach for kanban allocations. Omega 26(4), 483-493.

[12] Shahabudeen, P., and Sivakumar, G.D. 2008.Algorithm for the design of single-stage adaptive kanban system. Computers \& Industrial Engineering, 54(4), 800-820.

[13] Turner,R., Ingold, D., Lane, J.A., Madachy, R., and Anderson,D.2012. Effectiveness of kanban approaches in systems engineering within rapid response environments. Procedia Computer Science.8(309-314).

[14] Al-Tahat, M.D., and Mukattash, M. 2006. Design and analysis of production control scheme for Kanban-based JIT environment. Journal of the Franklin Institute, 343(4 5), 524-531.

[15] Hou, T., and Hu, w.2011. An integrated MOGA approach to determine the Pareto-optimal kanban number and size for a JIT system. Expert Systems with Applications, 38(5), 5912-5918.

[16] Wang, J.B., Wang, D., and Zhang, G.D. 2010. Singlemachine scheduling with learning functions. Applied Mathematics and Computation, 216 (4) , 1280-1286.

[17] Li, J., Yuan, X., and Xu, D. 2011. Setting due dates to minimize the total weighted possibilistic mean value of the weighted earliness tardiness costs on a single machine. Computers and Mathematics with Applications, $12,123-217$.

[18] Cheng, H., and Lio, H. 2010. A coordinated scheduling system for customer orders scheduling problem in job Shop environments. Expert Systems with Applications, 37 (10), 7831-7837.

[19] Erel, E., and Ghosh, B. 2007. Customer order scheduling on a single machine with family setup times: Complexity and algorithms. Applied Mathematics and Computation, 185 (7) $11-18$.

[20] Sheng, H., and Lio, C. 2009. Improving the delivery efficiency of the customer order scheduling problem in a job shop. Computers \& Industrial Engineering, 57 (3), 856-866.

[21] Wang, G., and Cheng, E. 2007. Customer order scheduling to minimize total weighted completion time. Omega, 35 (7) $623-626$.

[22] Chou, D. 2009.An experienced learning genetic algorithm to solve the single machine total weighted tardiness scheduling problem. Expert Systems with Applications, 36, 3857-3865.

[23] Wang, X. 2009. A opulation base variable neighborhood search for the single machine total weighted Tardiness problem. Computers \& Operations Research, 36 (9) 2105.

[24] Taherian, T., Mohammadi, M., and Bairamzadeh, S. 2011. A Scheduling Based Backlog Reduction Method in CONWIP Production Systems. International Journal of Computer Applications, (0975 - 8887) 32- No.5. 